\title{
The Mental Health Act Commission's “Guidelines": a further threat to psychiatric research
}

\author{
R E KENDELL
}

\section{Introduction}

Exciting developments in neuropharmacology and other brain sciences in the past decade have raised hopes that some real understanding of the aetiology of mental disorders such as schizophrenia and Alzheimer's disease may at last be within our grasp. Unfortunately, the ability of British psychiatry to respond to this opportunity has been damaged both by reduced government funding of the universities, resulting in a loss of academic posts and a disproportionate reduction in research time, and by a cumulative reduction in the Medical Research Council's grant in aid, resulting in steadily diminishing funds for clinical research. The latest, and potentially most serious, threat to psychiatric research comes from the Mental Health Act Commission.

\section{The code of practice and consent to treatment}

The 1983 Mental Health Act required the Secretary of State to draw up a code of practice, and the Mental Health Act Commission was given responsibility for preparing a draft of this code. The commission submitted its proposals to $\mathrm{Mr}$ Norman Fowler, Secretary of State for Social Services, in November 1985. It also circulated its views on "Consent to Treatment" to all health authorities, social service departments, and community health councils. These two documents contain wide ranging proposals, covering almost every aspect of psychiatric practice, including research.

Research is discussed in detail in the consent to treatment document, and three main kinds of clinical research are dis-

\footnotetext{
Edinburgh University Department of Psychiatry, Royal Edinburgh Hospital, Edinburgh EH10 5HF

R E KENDELL, FRCP, FRCPSYCH, professor
}

tinguished: physical interventions (for example, administration of drugs by injection), pharmacological interventions (for example, oral administration of drugs), and psychosocial interventions (for example, various forms of psychotherapy). The commission excludes from consideration, except with regard to issues of confidentiality, two other forms of research, which it calls "incidental" and "purely descriptive." The first refers to the use of blood samples, etc, obtained in the course of routine patient care. The meaning of the phrase "purely descriptive research" is unexplained, but two very dissimilar examples are given-the study of case records and "epidemiology." A further distinction is drawn between "therapeutic research," which may benefit the patients concerned (a controlled clinical trial, for example) and "non-therapeutic research," which will not. It is unclear where most of the common forms of clinical research come in this scheme. What, for example, is the status of a structured examination of mental state, of questionnaires or psychometric tests, of investigations such as electroencephalography, computed tomography, and nuclear magnetic resonance imaging, or the measurement of cerebral evoked potentials? Perhaps they are "epidemiology" and therefore of no concern to the commission. The general tenor of the document suggests, however, that they are "non-therapeutic" and therefore warrant "the greatest care and safeguards."

\section{The commission's "safeguards"}

The commission emphasises that it is not concerned with compulsorily detained patients alone, a special group for whom fairly strict safeguards are clearly required. In both the draft code of practice and the consent to treatment document it is stated unambiguously that "These guidelines apply as much to general practice as to hospital practice. They should be used as much for informal patients as for detained patients." The commission has therefore taken upon itself the task of laying down guidelines (which are referred to as rules elsewhere in the text) for all forms of research 
on patients with mental disorders of all kinds, formal or informal, in or out of hospital. It is questionable whether section 118 of the Mental Health Act gives authority for this major expansion of the scope of the code. There is also a notable lack of any reference in either document to the earlier recommendations of the Medical Research Council,' of the Royal College of Physicians, ${ }^{2}$ or of any of the other national or international bodies that have considered the ethics of clinical research. Moreover, although the commission emphasises the importance of local ethics committees, it clearly has little confidence in their ability to make appropriate decisions without a series of "safeguards" of its own devising.

The first of these safeguards is that every patient must be capable of giving consent and must give "real consent," a phrase which is defined at length elsewhere in the document. Moreover, "an even higher standard of certainty" is required "than when ordinary treatment is in question" and "all doubts should be resolved ... as tending to imply incapacity or lack of real consent." The second safeguard is that, for all non-therapeutic research, "a second opinion should be obtained from a consultant as to the capacity of the patient to consent and the reality of his consent... his (the consultant's) approval is essential." The third safeguard is that "the relatives of the patient should be fully informed, with the patient's consent."

These three safeguards are not intended as alternatives to one another, nor are they alternatives to careful scrutiny of the research protocol by a properly constituted ethics committee. All three must be applied in every case, whether the patient is detained or informal and in or out of hospital. Furthermore, any patients who are not capable of giving "real consent," whether or not they agree to what is asked of them and regardless of their relatives' views, "may not take part" in any project "if it involves any non-therapeutic research."

\section{Profoundly damaging effect}

If these "guidelines" were ever accepted by the Secretary of State in anything like their present form they would have a profoundly damaging effect on most forms of psychiatric research in this country. Clinical research into dementia would virtually cease, because of the absolute necessity, in the commission's view, for every patient participating in "non-therapeutic research" to give "real consent," and a series of obstacles would be placed in the path of many forms of research on patients of other kinds. If, for example, a psychiatrist wished to take a single blood sample from 40 or 50 of his own outpatients for research purposes it would no longer suffice for him to explain his plans to his health authority's ethics committee and then ask the patients' permission. A second consultant would have to interview every patient to ensure that they were both capable of giving real consent and actually doing so. The patients' relatives would also have to be contacted one by one to ensure that they too were "fully informed." Would the second consultant make a quick visit to the outpatient department every time one of the patients concerned arrived there or would he ask them all to return at a time more convenient for him? Would the patients' relatives be asked to take time off work to accompany them on their next outpatient attendance, or would they be visited at home so that what was proposed might be explained? Or would they simply be sent an explanatory letter? One has only to pose these questions to realise that the idea of obtaining blood samples would simply be abandoned. The commission's guidelines would make a simple and uncontentious proposal impracticable.

It is difficult to know whether the commission intends to inhibit research on psychiatric patients or whether a combination of ignorance about the realities of clinical research and careless drafting has led it to say things it did not intend to say. Certainly, none of the commission's 91 members has any substantial personal experience of clinical research. Fortunately, the commission's views are not yet binding on anyone. The consent to treatment document is merely an expression of the commission's views and the 209 page draft code of practice is just that, a draft. Its eventual format will be determined by the Secretary of State in the light of the advice he receives from his department and the comments submitted by interested parties.

\section{The importance of clinical research}

It is important, therefore, that everyone concerned should appreciate what is at stake here. The suffering caused by mental disorders and the economic burdens they impose are both very great. Some, like Huntington's chorea and Alzheimer's disease, are slowly and inexorably fatal. Others, like schizophrenia and manic depressive illness, of ten begin in adolescence or early adulthood and blight the subject's entire life. Few people, other than patients themselves and their families and the nurses and doctors who try to care for them, have any real understanding of the suffering caused. It is important that we should all recognise, and that members of the Mental Health Act Commission should recognise, that research is the only means by which any substantial reduction in that suffering can be achieved. However skilled and compassionate the nurses and psychiatrists caring for these patients are, however much money is devoted to psychiatric services, and however jealously the Mental Health Act Commission guards the legal rights of psychiatric patients, many will have their lives blighted and others will die prematurely because we do not have effective treatments to offer them. We have no effective treatments because we do not understand what is going wrong. Only research holds out any hope of providing that understanding and of curing or eliminating these disorders, and much of that research can be performed only on human patients. Rats develop nephritis and mice develop diabetes, and thus much useful research on such disorders can be done with rats and mice. Unfortunately, however, rats do not develop schizophrenia.

\section{Conclusion}

Regulations or guidelines that impose unnecessary constraints on clinical research benefit no one, least of all the mentally ill themselves, because the short term benefits for the few will almost certainly be outweighed by long term losses to many more. There is virtually no evidence that unwarranted investigations are currently being sanctioned by local ethics committees or that overzealous research workers exploit the mentally ill. There is no compelling reason, therefore, why the code of practice need say anything at all about research on informal patients or those living in the community. Their interests can be and are adequately safeguarded by ordinary ethics committees. Patients who are compulsorily detained in hospital are different, for they are more vulnerable and often less able to make appropriate decisions for themselves. They do require special safeguards and it is ironical that the commission had nothing to say on this subject. Let us hope, therefore, that wiser counsels will prevail before the amended code of practice is presented to parliament later this year.

\section{References}

1 Medical Research Council. Responsibility in investigations on human subjects. Report of Medical Research Council 1962-63. London: HMSO, 1963. (Cmnd 2382.)

2 Royal College of Physicians of London. Guidelines on the practice of ethics committees in medical research. London: Royal College of Physicians, 1984.

(Accepted 3 March 1986)

\section{Is there any evidence that the regular use of putty can cause pneumoconiosis?}

Putty is made in the United Kingdom from a mixture of calcium carbonate (whiting) and linseed oil. The mixture as laid down by British Standard 554 type 1 is $84 \%$ whiting in $16 \%$ linseed oil. There is no evidence that this mixture would cause pneumoconiosis. - J C WAGNER, pathologist, Penarth. 